\title{
Regulation of metabolism by the Mediator complex
}

\author{
Dou Yeon Youn ${ }^{1,2}$, Alus M. Xiaoli ${ }^{1,3}$, Jeffrey E. Pessin ${ }^{1,2}$, Fajun Yang ${ }^{1,3 \bowtie}$ \\ ${ }^{1}$ Division of Endocrinology, Department of Medicine, Diabetes Research Center, Albert Einstein College of Medicine, \\ Bronx, NY 10461, USA \\ 2 Department of Molecular Pharmacology, Albert Einstein College of Medicine, Bronx, NY 10461, USA \\ 3 Department of Developmental and Molecular Biology, Albert Einstein College of Medicine, Bronx, NY 10461, USA
}

Received: 14 January 2016 / Accepted: 15 February 2016 / Published online: 1 November 2016

\begin{abstract}
The Mediator complex was originally discovered in yeast, but it is conserved in all eukaryotes. Its bestknown function is to regulate RNA polymerase II-dependent gene transcription. Although the mechanisms by which the Mediator complex regulates transcription are often complicated by the contextdependent regulation, this transcription cofactor complex plays a pivotal role in numerous biological pathways. Biochemical, molecular, and physiological studies using cancer cell lines or model organisms have established the current paradigm of the Mediator functions. However, the physiological roles of the mammalian Mediator complex remain poorly defined, but have attracted a great interest in recent years. In this short review, we will summarize some of the reported functions of selective Mediator subunits in the regulation of metabolism. These intriguing findings suggest that the Mediator complex may be an important player in nutrient sensing and energy balance in mammals.
\end{abstract}

Keywords Transcription, Mediator, Cofactor, Metabolism, Insulin resistance, Obesity

\section{INTRODUCTION}

Gene transcription in eukaryotic cells is orchestrated through extremely complicated processes and multiple steps, including initiation, elongation, and termination, with the initiation being the most studied regulation step of gene expression. Disturbance of transcription initiation often results in serious diseases, such as cancer, in humans (Lee and Young 2013). Among the numerous different components in the initiation step of eukaryotic transcription, RNA polymerase II (Pol II) and the general transcription factors (TFIIB, TFIID, TFIIE, TFIIF, and TFIIH) constitute the basal transcription machinery, and specific sets of transcription factors are essential to determine the activation or repression of the target genes. However, it is generally believed that most of the transcription factors in eukaryotes are unable to directly interact with Pol II, which is

$\triangle$ Correspondence: fajun.yang@einstein.yu.edu (F. Yang) responsible for the production of all mRNAs. Studies in the past several decades suggest that this crucial gap is often filled by various transcription cofactors, which critically regulate the activation or repression in gene expression.

There is no doubt that human beings are currently experiencing an epidemic of obesity. As a result, the prevalence of type 2 diabetes (T2D) has sharply increased in the past decades. Dysregulation of genes in the pathways controlling glucose and/or lipid metabolism is common in states of insulin resistance and T2D, especially when patients are also diagnosed with nonalcoholic fatty liver disease (NAFLD) or cardiovascular disease (Brown and Goldstein 2008; Oh et al. 2013). The DNA-binding transcription factors and their cofactors have been one focus of the studies in the hope of understanding the molecular mechanisms that cause metabolic diseases. A few notable examples of transcription factors that regulate glucose and/or lipid metabolism include cAMP-regulated enhancer-binding 
protein (CREB), forkhead O box proteins (FoxOs), glucocorticoid receptor (GR), hepatic nuclear factors (HNFs), sterol response element binding protein-1c (SREBP-1c), carbohydrate response element binding protein (ChREBP), liver $\mathrm{X}$ receptors (LXRs), and peroxisome proliferator-activated receptor- $\gamma$ (PPAR $\gamma$ ) (Brown and Goldstein 2008; Oh et al. 2013; Lefterova et al. 2014). Among the transcription cofactors, a multisubunit protein assembly called the Mediator complex has been linked to several of these transcription factors (Malik and Roeder 2010; Taatjes 2010; Conaway and Conaway 2011; Allen and Taatjes 2015). Here, we summarize the current understanding on the regulation of transcription factors by individual subunits of the Mediator complex, focusing mainly on the metabolic involvement of the mediator subunits in mammals.

\section{The Mediator complex as a transcription cofactor}

The Mediator complex is able to bind to various transcription factors and integrates the transcriptional signals to the basal transcription machinery (Malik and Roeder 2010; Taatjes 2010; Conaway and Conaway 2011; Allen and Taatjes 2015). Originally discovered in yeast as a transcription cofactor (Kelleher et al. 1990; Flanagan et al. 1991; Kim et al. 1994), the mammalian Mediator complex has been given several different names in the early literature, including TRAP (thyroid hormone receptor-associated protein) (Fondell et al. 1996), ARC (activator-recruited cofactor) (Naar et al. 1999), or DRIP (vitamin D receptor-interacting protein) (Rachez et al. 1998). In HeLa cells, the Mediator complex can be biochemically isolated in at least two forms: the small mediator, also known as the core mediator (with a mass of about $600 \mathrm{kDa}$ ), that comprises up to 26 subunits organized into the head, middle, and tail sub-modules, and the large mediator (with a mass of about 1.2 $\mathrm{MDa}$ ), which additionally contains the kinase sub-module of four subunits-cyclin-dependent kinase 8 (CDK8), cyclin C (CycC), MED12, and MED13, but lacks the MED26 subunit (Taatjes et al. 2002). However, in other studies only the large Mediator complex was observed in the biochemical purifications (Wang et al. 2001; Sato et al. 2004). Nevertheless, it is generally believed that the Mediator complex is heterogeneous both structurally and functionally. In terms of functions, initial data suggested that the small mediator functions to activate transcription initiation in vitro, while the large mediator is inactive or acts as a transcription repressor (Taatjes et al. 2002). However, the large mediator has also been linked to transcription elongation (Donner et al. 2010). In addition, the mediator kinase module behaves in a context-specific manner to either repress or activate transcription, depending on the transcription factors and/or target gene promoters (Nemet et al. 2014).

Since the Mediator complex can directly bind to Pol II (Naar et al. 1999; Casamassimi and Napoli 2007; Taatjes 2010; Soutourina et al. 2011; Lariviere et al. 2012), collectively it may regulate many genes. However, studies on individual subunits of the Mediator complex revealed remarkable transcription factor and/ or tissue-specific functions for certain subunits. One example is that the MED15 subunit binds to and regulates SREBP-dependent transcription, while the MED25 subunit primarily controls VP16-mediated transcription (Mittler et al. 2003; Yang et al. 2004, 2006). Although it is unclear how many transcription factors could physically interact with the Mediator complex, it is less likely that all transcription factors need this complex to regulate target gene expression. For instance, currently there is no evidence that CREB or Myb can directly bind to the Mediator complex, and depletion of some subunits such as MED15 or MED25 had no effect on Myb-dependent gene transcription in HEK293 cells (Yang et al. 2004 , 2006). Moreover, the mediator subunit abundance and/or subcellular location may be different under different conditions. For example, feeding, obesity, NAFLD, and aging can cause a significant reduction of CDK8 and CycC proteins in the liver due to mTORC1 activation (Feng et al. 2015). Another example is that in response to stress, CycC undergoes translocation from the nucleus to the cytoplasm to regulate mitochondrial fission (Cooper et al. 2014; Wang et al. 2015). Although little is known about how the mediator subunit abundance is regulated, it may alter the Mediator complex composition and thus may have profound effects on the mediator-dependent functions.

Recent structure studies have demonstrated the presence of many different conformational assembly states of the Mediator complex (Tsai et al. 2014; Wang et al. 2014), indicating the intrinsic flexibility and heterogeneity. Moreover, the functions of the Mediator complex are now expanded to include the transcription elongation (Donner et al. 2010; Takahashi et al. 2011) and termination (Mukundan and Ansari 2011), and mRNA processing (Huang et al. 2012) and export (Schneider et al. 2015). Due to its massive size and complexity, however, the precise molecular mechanism(s) by which the Mediator complex regulates the gene-specific transcription remain poorly understood but are likely to play important functional roles in both normal physiological and pathophysiological states. 


\section{The head module}

The head module includes MED6, MED8, MED11, MED17, MED18, MED20, MED22, MED27, MED28, MED29, and MED30. This sub-module maintains the overall structure of the Mediator complex. The importance of the head module has been demonstrated from studies showing that yeast loss of MED17 prevents nearly all mRNA synthesis (Holstege et al. 1998; Thompson and Young 1995). Although it is unclear whether MED17 plays a similarly essential role in mammalian cells, a recent study reported that MED17 in the liver regulates lipogenic gene expression and lipid metabolism through the LXR transcription factors (Kim et al. 2015), providing a mechanism for the mediator regulation of lipid metabolism. Moreover, MED17 also binds to VP16, p53, and the estrogen receptor (ER) (Burakov et al. 2000; Park et al. 2003; Mehta et al. 2009; Meyer et al. 2010; Kumafuji et al. 2014). Similarly, PPAR $\gamma$ interacts with both MED1 (Zhu et al. 1997; Yuan et al. 1998; Ge et al. 2008) and MED14 (Grontved et al. 2010) subunits of the middle and tail modules, respectively. Thus, it appears that a given transactivation domain sometimes recruits the Mediator complex by binding to more than one subunit.

It is the current understanding that the head and middle modules may bind to either Pol II or the kinase module in an exclusive manner (Knuesel et al. 2009a; Naar et al. 2002). The head module is thought to provide the greatest impact in controlling overall transcription primarily by shifting the transcription machinery from active to inactive state rather than serving as a binding site for other transcriptional regulators. The electron microscopy-derived structure and affinity pull-down experiments have identified MED17 as the main subunit that directly interacts with Pol II and promotes the transcription initiation of selected genes (Soutourina et al. 2011). Interestingly, the head module subunit MED30 is a metazoan-specific subunit, and a missense mutation of MED30 in mice resulted in a pleiotropic decrease in transcription of cardiac genes that are necessary for oxidative phosphorylation and mitochondrial integrity (Krebs et al. 2011). The mutation effect of MED30 can be partially protected by a ketogenic diet through increasing the expression of genes, such as Pgc1a and Sod2 (Krebs et al. 2011). This study suggests a critical role of MED30 in metabolism, but the regulatory mechanism(s) shall be investigated in the future.

\section{MED1 provides a docking surface for nuclear receptors}

The middle module includes subunits of MED1, MED4, MED7, MED9, MED10, MED19, MED21 MED26, and
MED31. The MED26 subunit is a specific subunit of the small mediator (Taatjes et al. 2002) and it is required for transcription elongation (Takahashi et al. 2011). The most studied subunit of the middle module is MED1, but metabolic functions of other subunits in the middle module remain to be investigated.

MED1 is able to interact with numerous transcription factors or cofactors, including PPAR $\alpha, \operatorname{PPAR} \gamma, \mathrm{GR}$, C/EBP $\beta$, and PGC1 $\alpha$, which are all implicated in metabolic regulation (Zhu et al. 1997; Yuan et al. 1998) (See Jia et al. 2014 for a recent review on MED1). Although deletion of MED1 results in embryonic lethality at E11.5, the MED1 conditional knockout or mutant mice play an important role in adipogenesis through $\operatorname{PPAR} \gamma$, fatty acid oxidation through PPAR $\alpha$, mammary gland development through ER, liver steatosis through GR and constitutive androstane receptor (CAR), thermogenesis regulation through uncoupling protein 1 (UCP1) upregulation, skeletal muscle function, and insulin signaling (Ge et al. 2002; Jia et al. 2004, 2009; Jiang et al. 2010; Iida et al. 2015).

Similar to the steroid receptor co-activator (SRC) and PGC1 families of transcription cofactors, MED1 contains two LXXLL motifs [located within amino acid (aa) 589-593 and 630-634, respectively] that provide the binding surfaces for various nuclear receptors, and either one of the LXXLL motifs is sufficient for proteinprotein interactions (Chang et al. 1999; Ge et al. 2008). A dominant negative form of MED1 with mutant LXXLL motifs reduces the transcription activity of nuclear receptors and suppresses PPAR $\gamma$-induced adipogenesis (Ge et al. 2002). However, these LXXLL motifs are not required for MED1 regulation of PPAR $\gamma$ in cultured MEFs, suggesting MED1 regulation of gene transcription through alternative mechanisms in a context-dependent manner. Moreover, the conserved N-terminus (aa1-530) of MED1 is also important for PPAR $\gamma$-target gene expression (Ge et al. 2008). Deletion of MED1 in mouse liver abrogates PPAR $\alpha$-activated peroxisomal proliferation (Jia et al. 2004) and acetaminophen-induced hepatotoxicity through CAR (Jia et al. 2005). Moreover, liver-specific knockout of MED1 protects mice from excessive fat accumulation under high-fat diet, whereas the wild-type mice exhibited fatty liver (Bai et al. 2011).

Recently, MED1 has been found to interact with PRDM16, a key inducer of brown adipose tissue (BAT)selective genes (Harms et al. 2015; Iida et al. 2015). Directly interacting with the N-terminus of MED1, PRDM16 promotes Ucp1 gene expression in brown adipocytes (Iida et al. 2015). ChIP-Seq and ChIP-qPCR analyses show that MED1 is recruited to the enhancer sites of BAT-selective genes such as Ucp1, Cidea, Ppara, and Pgc1a in the wild-type, but not in PRDM16 
knockout brown adipocytes (Harms et al. 2015). Furthermore, skeletal muscle-specific knockout of MED1 increased gene expression of Ucp1 and Cidea, and promoted mitochondrial density in white glycolytic skeletal muscles and respiratory uncoupling (Chen et al. 2010). The regulatory roles of MED1 in major metabolic organs, such as liver, adipose tissues, and skeletal muscle, suggest that MED1 is an important regulator for metabolic gene expression. However, it is difficult to know whether the function(s) of MED1 are all mediator dependent or not.

\section{The tail module directly interacts with various transcription factors}

The tail module includes subunits of MED14, MED15, MED16, MED23, MED24, and MED25. The metabolic roles of this module are well established, particularly for MED14, MED15, and MED23.

MED14 has been implicated in regulation of lipid homeostasis. It has been reported that MED14 binds to the N-terminal AF1 domain of GR (Hittelman et al. 1999) or PPAR $\gamma$ (Grontved et al. 2010) to activate target gene transcription. In vitro and in vivo assays show that MED14 directly interacts with GR, and this interaction increased GR-dependent transcription activation (Hittelman et al. 1999). In addition, MED14 directly interacts with PPAR $\gamma$ and promotes PPAR $\gamma$-dependent transactivation as well as the recruitment of the Mediator complex (Grontved et al. 2010). Recently, it has been demonstrated that the Mediator complex is recruited to the PPAR $\gamma$-target gene promoters without the LXXLL motifs of MED1, suggesting that MED14 may be more critically required for the transcription activation during adipogenesis (Grontved et al. 2010). Studies of MED14 knockdown revealed that the recruitment of PPAR $\gamma$, MED6, MED8, and Pol II to the transcription start sites is dependent on MED14 in 3T3-L1 cells (Grontved et al. 2010). At present, it is unclear what the basis is for the apparent conflicting roles of MED1 and MED14 in the regulation of PPAR $\gamma$-target genes. It remains to be established whether these differences reflect the different experimental interventions used, differences in cells examined, or differential interactions and physiologic outputs that occur during adipogenesis versus fully differentiated adipocytes. In addition, there may be undetermined cell-context effects resulting from the secondary transcription factor interactions. For example, MED14 was also reported to interact with the SREBP transcription factors (Toth et al. 2004).

The functions of MED15 and other mediator subunits in worms have been recently reviewed (Grants et al. 2015). In mammalian cells, MED15 acts as an important regulator of lipid biosynthesis through modulating the SREBPs (Yang et al. 2006). The interaction between MED15 and SREBPs is through the MED15-KIX domain, which is structurally similar to the KIX domains of CBP and p300 (Yang et al. 2006). Interestingly, the KIX domain of MED15 interacts only with SREBP-1a, but not with several other transcription factors examined, suggesting its binding specificity. The SREBP-target genes include the important lipogenic and cholesterogenic genes such as fatty acid synthase (Fasn) and HMG-CoA synthase (Hmgcr) (Amemiya-Kudo et al. 2002). By recruiting the Mediator complex upon binding to SREBPs, MED15 promotes SREBP-target gene expression (Naar et al. 1998, 1999). Interestingly, smallmolecule inhibitors that block the interaction between the MED15-KIX domain and the transactivation domain of SREBP-1a protect mice from the metabolic dysregulation that occurs during diet-induced obesity (Zhao et al. 2014).

MED23 has been well studied in mammalian model systems. The importance of MED23 in viability has been shown with the embryonic lethality when MED23 was knocked out in mice (Balamotis et al. 2009). MED23 has been linked to insulin signaling in the adipogenesis transcription cascade (Wang et al. 2009). In 3T3-L1 cells, it has been shown that the interaction of MED23 with Elk1 is enhanced by the insulin-induced MAPK activation, resulting in further induction of Krox20, the initial transcription factor in the adipogenesis pathway (Wang et al. 2009). Interestingly, a recent study has shown that MED23 is also involved in regulating the differentiation of mesenchymal stem cells into smooth muscle cells or adipocytes (Yin et al. 2012). MED23 deficiency promoted mesenchymal stem cells into smooth muscle cells while preventing the differentiation into adipocytes (Yin et al. 2012). The mechanism by which MED23 controls the differentiation is via regulating the balance of serum response factor (SRF) downstream genes, RhoA/MAL or Ras/ELK1, by directly interacting with them in response to upstream signals (Stevens et al. 2002; Wang et al. 2009; Yin et al. 2012). MED23 favors the ELK1-SRF complex formation, which in turn facilitates the growth-related and adipogenic genes and suppresses the cytoskeleton and smooth muscle gene transcription (Yin et al. 2012). Furthermore, another recent report revealed that liver-specific knockdown or knockout of MED23 significantly improved glucose and lipid metabolism, especially for mice that were fed a high-fat diet (Chu et al. 2014). Reduced Fox01-target gene expression was found in MED23-deficient primary hepatocytes, demonstrating that the regulation of MED23 on gluconeogenic gene expression is through FoxO1 (Chu et al. 2014). 
Regulation of the balance between adipocyte and smooth muscle development as well as hepatic lipid/ glucose metabolism by MED23 suggests the importance of this subunit in metabolism.

It is known that HNF4 $\alpha$ regulates a various set of genes that are not only involved in early development but also in liver and pancreatic cell differentiation, glucose metabolism, and lipid homeostasis (Odom et al. 2004). In yeast two-hybrid assays, MED25 was found to bind to HNF4 $\alpha$, inducing HNF4 $\alpha$-dependent gene transcription that maintains the normal function of insulin secretion in pancreatic $\beta$-cells (Odom et al. 2004). As a subunit in the tail module, MED25 interaction with HNF $4 \alpha$ recruits the Mediator complex and Pol II for transcriptional activation (Rana et al. 2011). Although the exact mechanism is still unclear, these functional studies also suggest a role of MED25 in metabolism and lipid homeostasis.

\section{The kinase module functions in a context- dependent manner}

Originally considered as a part of a transcriptional repressor in the large Mediator complex, the kinase module can repress or activate gene expression through kinase-dependent or kinase-independent mechanisms (Malik and Roeder 2010). Interestingly, the small mediator subunit MED26 is present in a mutually exclusive manner with CDK8 (Taatjes et al. 2002). Moreover, the kinase activity of CDK8 is not always required for its function in gene expression (Holstege et al. 1998). Besides the four conserved subunits in this module, paralogues have been identified for CDK8, MED12, and MED13, i.e., CDK19, MED12L, and MED13L (Daniels et al. 2013). Although their biological functions are less clear, these paralogues are subunits of the mammalian Mediator complex in a mutually exclusive manner with CDK8, MED12, and MED13 (Daniels et al. 2013). Among the four subunits, the evolutionarily conserved CDK8 and CycC have been studied for their functions in lipogenic gene expression (Zhao et al. 2012). The tissue-specific CDK19 is highly similar to CDK8 in amino acid sequence, but they may have both overlapping and distinct functions (Tsutsui et al. 2011). For instance, CDK8 but not CDK19 regulates HIF1-dependent gene expression (Galbraith et al. 2013). Recent studies also revealed the functional roles of MED12, MED13, and MED13L in cardiovascular and systemic metabolic regulation in both physiological and pathophysiological states.

The CDK8-CycC dimer negatively regulates de novo lipogenesis by reducing nuclear SREBP-1a or SREBP-1c protein stability (Zhao et al. 2012). SREBP-1a and SREBP-1c are key regulators of de novo lipogenesis, and posttranslational modifications represent critical mechanisms that regulate their activity and/or abundance (Brown and Goldstein 2008). In addition to acetylation/ deacetylation and ubiquitination, the phosphorylation of nuclear forms of SREBP-1 is critical for the proteasomemediated degradation (Sundqvist et al. 2005). Therefore, the direct phosphorylation of threonine 426 or 402 in SREBP-1a and SREBP-1c isoforms, respectively, by CDK8 is important to understand the mechanism of SREBP-1 regulation of lipid metabolism (Zhao et al. 2012). The functions of CDK8-CycC dimer may be independent of the Mediator complex, as up to $30 \%$ of CDK8 exists as a free form from the Mediator complex although the presence of MED12 is required for maximal kinase activity of CDK8 (Knuesel et al. 2009b). Interestingly, insulin stimulation in vitro and in vivo can reduce the protein levels of CDK8 and CycC (Zhao et al. 2012). In mouse livers, CDK8 knockdown increased the blood lipid levels and NAFLDlike phenotypes (Zhao et al. 2012). Recent data have further suggested that mTORC1 activation upon feeding or in states of insulin resistance or NAFLD is responsible for the down-regulation of CDK8 and CycC in the liver (Feng et al. 2015).

In addition to CDK8 function in the negative regulation of de novo lipogenesis through its kinase activity, it has been shown that CDK8 has a positive role in response to serum, likely at the elongation step instead of the initiation step where CDK8 is a negative regulator (Donner et al. 2010) (see (Nemet et al. 2014) for a recent review). The difficulty of identification of CDK8 substrates in vivo lies with embryonic lethality of CDK8deficient mice, whereas there is no effect on cell viability in some cultured cells (Westerling et al. 2007). Nevertheless, using a selective inhibitor of CDK8 and CDK19 in tissue culture, a recent study has added more potential substrates of CDK8 and/or CDK19 to the increasing list (Poss et al. 2016), which includes Cyclin H (Akoulitchev et al. 2000), Notch (Fryer et al. 2004), histone H3 (Knuesel et al. 2009b), Smads (Alarcon et al. 2009), SREBP-1 (Zhao et al. 2012), E2F1 (Zhao et al. 2013), and STAT1 (Bancerek et al. 2013; Putz et al. 2013). However, further studies are necessary to understand the roles of CDK8 and CDK19 in metabolic regulation.

Through MED13, the MED12-MED13 dimer links the small mediator as well as the CDK8-CycC dimer (Tsai et al. 2013). Although the mechanism is unclear, MED12 can activate the Mediator complex-independent kinase activity of CDK8 in vitro (Knuesel et al. 2009b). Interestingly, MED13 in the heart regulates a subset of nuclear hormone receptor target genes that are major determinants of the metabolic rate and whole-body energy expenditure (Grueter et al. 2012). MED13 overexpression 
in the heart resulted in an increase in energy expenditure and resistance to diet-induced obesity (Grueter et al. 2012). MED13 is a target of miR-208a, one of the several microRNAs that are encoded by the cardiac-specific $\alpha$ myosin heavy chain gene intron and are involved in heart disease and metabolic regulation (Montgomery et al. 2011; Grueter et al. 2012). Inhibition of miR-208a resulted in a similar metabolic phenotype that agrees with the finding that miR-208a negatively regulates MED13 (Grueter et al. 2012). Elevated protein levels of MED13 in the heart resulted in a significant increase in oxygen consumption, whereas the cardiac deletion of MED13 resulted in increased lipid accumulation without changes in food intake in mice (Grueter et al. 2012). MED13, but not MED13L, controls the whole-body metabolic homeostasis through altering metabolic profiles in white adipose tissue and liver when MED13 is altered in the heart (Baskin et al. 2014). Moreover, cardiac overexpression of MED13 in mice improves dysregulation of energy metabolism under high-fat diet likely through unknown circulating factors, as determined by heterotypic parabiosis experiments (Baskin et al. 2014). However, MED13 knockout in skeletal muscle resulted in resistance to hepatic steatosis in mice by activating a metabolic gene program that enhances muscle glucose uptake and storage as glycogen (Amoasii et al. 2016). Mechanistically, MED13 suppresses the expression of genes involved in glucose uptake and metabolism in skeletal muscle by inhibiting the nuclear receptor NURR1 and the MEF2 transcription factor (Amoasii et al. 2016). Although the roles of MED13 in other metabolic tissues have not been reported, the opposing metabolic regulation by MED13 in skeletal muscle and the heart further demonstrates the tissue-specific functions of the Mediator complex.

To date, not much information is available on the functions of MED12L and MED13L. Expressed in both heart and brain, MED13L is associated with early development of both heart and brain since its missense mutations and gene interruption are found in patients with congenital heart defect, learning disabilities, and facial anomalies (Muncke et al. 2003; Asadollahi et al. 2013; Davis et al. 2013). Both MED13 and MED13L are degraded by the SCF/Fbw7-dependent ubiquitination mechanism, and similar to MED13, MED13L may be also responsible for linking the kinase module to the small Mediator complex (Davis et al. 2013).

\section{CONCLUSION}

Since the discovery of the Mediator complex as a transcription cofactor of eukaryotes, its subunits have been associated with various biological processes and several diseases ranging from developmental defects to cancer in animal models and humans. The metabolic functions of the Mediator complex have become increasingly significant. In most cases, the Mediator complex functions as a bridge to connect and integrate specific transcription factors to the basal transcription machinery, resulting in expression changes of a selective set of genes. In addition to the presence of many subunits, tissue-specific expression and possible diverse assembly states at different physiological conditions further complicate the biological functions of the Mediator complex. Future studies on the role of the Mediator complex in metabolism may include identification of how the metabolic or nutrient signals may regulate the assembly states and subunit compositions and investigation of tissue-specific functions of each subunit in regulating nutrient and energy metabolism in vivo.

$\begin{array}{ll}\text { Abbreviations } \\ \text { Pol II } & \text { RNA polymerase II } \\ \text { T2D } & \text { Type 2 diabetes } \\ \text { NAFLD } & \text { Non-alcoholic fatty liver disease } \\ \text { CREB } & \text { cAMP-regulated enhancer-binding protein } \\ \text { FoxO } & \text { Forkhead O box protein } \\ \text { GR } & \text { Glucocorticoid receptor } \\ \text { HNF } & \text { Hepatic nuclear factor } \\ \text { SREBP } & \text { Sterol response element binding protein } \\ \text { LXR } & \text { Liver X receptor } \\ \text { PPAR } & \text { Peroxisome proliferator-activated receptor } \\ \text { CDK } & \text { Cyclin-dependent kinase } \\ \text { CycC } & \text { Cyclin C } \\ \text { ER } & \text { Estrogen receptor } \\ \text { CAR } & \text { Constitutive androstane receptor } \\ \text { UCP1 } & \text { Uncoupling protein 1 } \\ \text { SRC } & \text { Steroid receptor co-activator } \\ \text { BAT } & \text { Brown adipose tissue } \\ \text { SRF } & \text { Serum response factor }\end{array}$

Acknowledgments This work was supported by Grants from the National Institutes of Health (DK020541, DK093623, DK098439, and DK110063). We apologize for being unable to cite all original studies due to the space limitation.

\section{Compliance with Ethical Standards}

Conflict of interest The authors declare that they have no conflict of interest.

Human and Animal Rights and Informed Consent This article does not contain any studies with human or animal subjects performed by any of the authors. 
Open Access This article is distributed under the terms of the Creative Commons Attribution 4.0 International License (http:// creativecommons.org/licenses/by/4.0/), which permits unrestricted use, distribution, and reproduction in any medium, provided you give appropriate credit to the original author(s) and the source, provide a link to the Creative Commons license, and indicate if changes were made.

\section{References}

Akoulitchev S, Chuikov S, Reinberg D (2000) TFIIH is negatively regulated by cdk8-containing mediator complexes. Nature 407:102-106

Alarcon C, Zaromytidou AI, Xi Q Gao S, Yu J, Fujisawa S, Barlas A, Miller AN, Manova-Todorova K, Macias MJ, Sapkota G, Pan D, Massagué J (2009) Nuclear CDKs drive Smad transcriptional activation and turnover in BMP and TGF-beta pathways. Cell 139:757-769

Allen BL, Taatjes DJ (2015) The Mediator complex: a central integrator of transcription. Nat Rev Mol Cell Biol 16:155-166

Amemiya-Kudo M, Shimano H, Hasty AH, Yahagi N, Yoshikawa T, Matsuzaka T, Okazaki H, Tamura Y, Iizuka Y, Ohashi K, Osuga J, Harada K, Gotoda T, Sato R, Kimura S, Ishibashi S, Yamada N (2002) Transcriptional activities of nuclear SREBP-1a, -1c, and -2 to different target promoters of lipogenic and cholesterogenic genes. J Lipid Res 43:1220-1235

Amoasii L, Holland W, Sanchez-Ortiz E, Baskin KK, Pearson M, Burgess SC, Nelson BR, Bassel-Duby R, Olson EN (2016) A MED13-dependent skeletal muscle gene program controls systemic glucose homeostasis and hepatic metabolism. Genes Dev 30:434-446

Asadollahi R, Oneda B, Sheth F, Azzarello-Burri S, Baldinger R, Joset P, Latal B, Knirsch W, Desai S, Baumer A, Houge G, Andrieux J, Rauch A (2013) Dosage changes of MED13L further delineate its role in congenital heart defects and intellectual disability. Eur J Hum Genet 21:1100-1104

Bai L, Jia Y, Viswakarma N, Huang J, Vluggens A, Wolins NE, Jafari N, Rao MS, Borensztajn J, Yang G, Reddy JK (2011) Transcription coactivator mediator subunit MED1 is required for the development of fatty liver in the mouse. Hepatology 53:1164-1174

Balamotis MA, Pennella MA, Stevens JL, Wasylyk B, Belmont AS, Berk AJ (2009) Complexity in transcription control at the activation domain-mediator interface. Sci Signal 2:ra20

Bancerek J, Poss ZC, Steinparzer I, Sedlyarov V, Pfaffenwimmer T, Mikulic I, Dolken L, Strobl B, Muller M, Taatjes DJ, Kovarik P (2013) CDK8 kinase phosphorylates transcription factor STAT1 to selectively regulate the interferon response. Immunity 38:250-262

Baskin KK, Grueter CE, Kusminski CM, Holland WL, Bookout AL, Satapati S, Kong YM, Burgess SC, Malloy CR, Scherer PE, Newgard CB, Bassel-Duby R, Olson EN (2014) MED13dependent signaling from the heart confers leanness by enhancing metabolism in adipose tissue and liver. EMBO Mol Med 6:1610-1621

Brown MS, Goldstein JL (2008) Selective versus total insulin resistance: a pathogenic paradox. Cell Metab 7:95-96

Burakov D, Wong CW, Rachez C, Cheskis BJ, Freedman LP (2000) Functional interactions between the estrogen receptor and DRIP205, a subunit of the heteromeric DRIP coactivator complex. J Biol Chem 275:20928-20934

Casamassimi A, Napoli C (2007) Mediator complexes and eukaryotic transcription regulation: an overview. Biochimie 89:1439-1446
Chang C, Norris JD, Gron H, Paige LA, Hamilton PT, Kenan DJ, Fowlkes D, McDonnell DP (1999) Dissection of the LXXLL nuclear receptor-coactivator interaction motif using combinatorial peptide libraries: discovery of peptide antagonists of estrogen receptors alpha and beta. Mol Cell Biol 19:8226-8239

Chen W, Zhang X, Birsoy K, Roeder RG (2010) A muscle-specific knockout implicates nuclear receptor coactivator MED1 in the regulation of glucose and energy metabolism. Proc Natl Acad Sci USA 107:10196-10201

Chu Y, Gomez Rosso L, Huang P, Wang Z, Xu Y, Yao X, Bao M, Yan J, Song H, Wang G (2014) Liver Med23 ablation improves glucose and lipid metabolism through modulating FOXO1 activity. Cell Res 24:1250-1265

Conaway RC, Conaway JW (2011) Origins and activity of the Mediator complex. Semin Cell Dev Biol 22:729-734

Cooper KF, Khakhina S, Kim SK, Strich R (2014) Stress-induced nuclear-to-cytoplasmic translocation of cyclin $\mathrm{C}$ promotes mitochondrial fission in yeast. Dev Cell 28:161-173

Daniels DL, Ford M, Schwinn MK, Benink H, Galbraith MD, Amunugama R, Jones R, Allen D, Okazaki N, Yamakawa H, Miki F, Nagase T, Espinosa JM, Urh M (2013) Mutual exclusivity of MED12/MED12L, MED13/13L, and CDK8/19 paralogs revealed within the CDK-mediator kinase module. J Proteomics Bioinform. doi:10.4172/jpb.S4172-4004

Davis MA, Larimore EA, Fissel BM, Swanger J, Taatjes DJ, Clurman BE (2013) The SCF-Fbw7 ubiquitin ligase degrades MED13 and MED13L and regulates CDK8 module association with mediator. Genes Dev 27:151-156

Donner AJ, Ebmeier CC, Taatjes DJ, Espinosa JM (2010) CDK8 is a positive regulator of transcriptional elongation within the serum response network. Nat Struct Mol Biol 17:194-201

Feng D, Youn DY, Zhao X, Gao Y, Quinn WJ 3rd, Xiaoli AM, Sun Y, Birnbaum MJ, Pessin JE, Yang F (2015) mTORC1 downregulates cyclin-dependent kinase 8 (CDK8) and cyclin $\mathrm{C}$ (CycC). PLoS One 10:e0126240

Flanagan PM, Kelleher RJ 3rd, Sayre MH, Tschochner H, Kornberg RD (1991) A mediator required for activation of RNA polymerase II transcription in vitro. Nature 350:436-438

Fondell JD, Ge H, Roeder RG (1996) Ligand induction of a transcriptionally active thyroid hormone receptor coactivator complex. Proc Natl Acad Sci USA 93:8329-8333

Fryer CJ, White JB, Jones KA (2004) Mastermind recruits CycC:CDK8 to phosphorylate the Notch ICD and coordinate activation with turnover. Mol Cell 16:509-520

Galbraith MD, Allen MA, Bensard CL, Wang X, Schwinn MK, Qin B, Long HW, Daniels DL, Hahn WC, Dowell RD, Espinosa JM (2013) HIF1A employs CDK8-mediator to stimulate RNAPII elongation in response to hypoxia. Cell 153:1327-1339

Ge K, Guermah M, Yuan CX, Ito M, Wallberg AE, Spiegelman BM, Roeder RG (2002) Transcription coactivator TRAP220 is required for PPAR gamma 2-stimulated adipogenesis. Nature 417:563-567

Ge K, Cho YW, Guo H, Hong TB, Guermah M, Ito M, Yu H, Kalkum M, Roeder RG (2008) Alternative mechanisms by which mediator subunit MED1/TRAP220 regulates peroxisome proliferator-activated receptor gamma-stimulated adipogenesis and target gene expression. Mol Cell Biol 28:1081-1091

Grants JM, Goh GY, Taubert S (2015) The Mediator complex of Caenorhabditis elegans: insights into the developmental and physiological roles of a conserved transcriptional coregulator. Nucleic Acids Res 43:2442-2453

Grontved L, Madsen MS, Boergesen M, Roeder RG, Mandrup S (2010) MED14 tethers mediator to the N-terminal domain of peroxisome proliferator-activated receptor gamma and is required for full transcriptional activity and adipogenesis. Mol Cell Biol 30:2155-2169 
Grueter CE, van Rooij E, Johnson BA, DeLeon SM, Sutherland LB, Qi $\mathrm{X}$, Gautron L, Elmquist JK, Bassel-Duby R, Olson EN (2012) A cardiac microRNA governs systemic energy homeostasis by regulation of MED13. Cell 149:671-683

Harms MJ, Lim HW, Ho Y, Shapira SN, Ishibashi J, Rajakumari S, Steger DJ, Lazar MA, Won KJ, Seale P (2015) PRDM16 binds MED1 and controls chromatin architecture to determine a brown fat transcriptional program. Genes Dev 29:298-307

Hittelman AB, Burakov D, Iniguez-Lluhi JA, Freedman LP, Garabedian MJ (1999) Differential regulation of glucocorticoid receptor transcriptional activation via AF-1-associated proteins. The EMBO journal 18:5380-5388

Holstege FC, Jennings EG, Wyrick JJ, Lee TI, Hengartner CJ, Green MR, Golub TR, Lander ES, Young RA (1998) Dissecting the regulatory circuitry of a eukaryotic genome. Cell 95:717-728

Huang Y, Li W, Yao X, Lin QJ, Yin JW, Liang Y, Heiner M, Tian B, Hui J, Wang G (2012) Mediator complex regulates alternative mRNA processing via the MED23 subunit. Mol Cell 45:459-469

Iida S, Chen W, Nakadai T, Ohkuma Y, Roeder RG (2015) PRDM16 enhances nuclear receptor-dependent transcription of the brown fat-specific Ucp1 gene through interactions with Mediator subunit MED1. Genes Dev 29:308-321

Jia Y, Qi C, Kashireddi P, Surapureddi S, Zhu YJ, Rao MS, Le Roith D, Chambon P, Gonzalez FJ, Reddy JK (2004) Transcription coactivator $\mathrm{PBP}$, the peroxisome proliferator-activated receptor (PPAR)-binding protein, is required for PPARalpha-regulated gene expression in liver. J Biol Chem 279:24427-24434

Jia Y, Guo GL, Surapureddi S, Sarkar J, Qi C, Guo D, Xia J, Kashireddi P, Yu S, Cho YW, Rao MS, Kemper B, Ge K, Gonzalez FJ, Reddy JK (2005) Transcription coactivator peroxisome proliferatoractivated receptor-binding protein/mediator 1 deficiency abrogates acetaminophen hepatotoxicity. Proc Natl Acad Sci USA 102:12531-12536

Jia Y, Viswakarma N, Fu T, Yu S, Rao MS, Borensztajn J, Reddy JK (2009) Conditional ablation of mediator subunit MED1 (MED1/PPARBP) gene in mouse liver attenuates glucocorticoid receptor agonist dexamethasone-induced hepatic steatosis. Gene Expr 14:291-306

Jia Y, Viswakarma N, Reddy JK (2014) Med1 subunit of the mediator complex in nuclear receptor-regulated energy metabolism, liver regeneration, and hepatocarcinogenesis. Gene Expr 16:63-75

Jiang P, Hu Q Ito M, Meyer S, Waltz S, Khan S, Roeder RG, Zhang X (2010) Key roles for MED1 LxxLL motifs in pubertal mammary gland development and luminal-cell differentiation. Proc Natl Acad Sci USA 107:6765-6770

Kelleher RJ 3rd, Flanagan PM, Kornberg RD (1990) A novel mediator between activator proteins and the RNA polymerase II transcription apparatus. Cell 61:1209-1215

Kim YJ, Bjorklund S, Li Y, Sayre MH, Kornberg RD (1994) A multiprotein mediator of transcriptional activation and its interaction with the C-terminal repeat domain of RNA polymerase II. Cell 77:599-608

Kim GH, Oh GS, Yoon J, Lee GG, Lee KU, Kim SW (2015) Hepatic TRAP80 selectively regulates lipogenic activity of liver $\mathrm{X}$ receptor. J Clin Investig 125:183-193

Knuesel MT, Meyer KD, Bernecky C, Taatjes DJ (2009a) The human CDK8 subcomplex is a molecular switch that controls Mediator coactivator function. Genes Dev 23:439-451

Knuesel MT, Meyer KD, Donner AJ, Espinosa JM, Taatjes DJ (2009b) The human CDK8 subcomplex is a histone kinase that requires Med12 for activity and can function independently of mediator. Mol Cell Biol 29:650-661

Krebs P, Fan W, Chen YH, Tobita K, Downes MR, Wood MR, Sun L, Li X, Xia Y, Ding N, Spaeth JM, Moresco EM, Boyer TG, Lo CW,
Yen J, Evans RM, Beutler B (2011) Lethal mitochondrial cardiomyopathy in a hypomorphic Med30 mouse mutant is ameliorated by ketogenic diet. Proc Natl Acad Sci USA 108:19678-19682

Kumafuji M, Umemura H, Furumoto T, Fukasawa R, Tanaka A, Ohkuma Y (2014) Mediator MED18 subunit plays a negative role in transcription via the $\mathrm{CDK} /$ cyclin module. Genes Cells 19:582-593

Lariviere L, Plaschka C, Seizl M, Wenzeck L, Kurth F, Cramer P (2012) Structure of the Mediator head module. Nature 492:448-451

Lee TI, Young RA (2013) Transcriptional regulation and its misregulation in disease. Cell 152:1237-1251

Lefterova MI, Haakonsson AK, Lazar MA, Mandrup S (2014) PPARgamma and the global map of adipogenesis and beyond. Trends Endocrinol Metab 25:293-302

Malik S, Roeder RG (2010) The metazoan Mediator co-activator complex as an integrative hub for transcriptional regulation. Nat Rev Genet 11:761-772

Mehta S, Miklos I, Sipiczki M, Sengupta S, Sharma N (2009) The Med8 mediator subunit interacts with the Rpb4 subunit of RNA polymerase II and Ace2 transcriptional activator in Schizosaccharomyces pombe. FEBS Lett 583:3115-3120

Meyer KD, Lin SC, Bernecky C, Gao Y, Taatjes DJ (2010) p53 activates transcription by directing structural shifts in Mediator. Nat Struct Mol Biol 17:753-760

Mittler G, Stuhler T, Santolin L, Uhlmann T, Kremmer E, Lottspeich F, Berti L, Meisterernst M (2003) A novel docking site on Mediator is critical for activation by VP16 in mammalian cells. EMBO J 22:6494-6504

Montgomery RL, Hullinger TG, Semus HM, Dickinson BA, Seto AG, Lynch JM, Stack C, Latimer PA, Olson EN, van Rooij E (2011) Therapeutic inhibition of miR-208a improves cardiac function and survival during heart failure. Circulation 124:1537-1547

Mukundan B, Ansari A (2011) Novel role for mediator complex subunit Srb5/Med18 in termination of transcription. J Biol Chem 286:37053-37057

Muncke N, Jung C, Rudiger H, Ulmer H, Roeth R, Hubert A, Goldmuntz E, Driscoll D, Goodship J, Schon K, Rappold G (2003) Missense mutations and gene interruption in PROSIT240, a novel TRAP240-like gene, in patients with congenital heart defect (transposition of the great arteries). Circulation 108:2843-2850

Naar AM, Beaurang PA, Robinson KM, Oliner JD, Avizonis D, Scheek S, Zwicker J, Kadonaga JT, Tjian R (1998) Chromatin, TAFs, and a novel multiprotein coactivator are required for synergistic activation by Sp1 and SREBP-1a in vitro. Genes Dev 12:3020-3031

Naar AM, Beaurang PA, Zhou S, Abraham S, Solomon W, Tjian R (1999) Composite co-activator ARC mediates chromatindirected transcriptional activation. Nature 398:828-832

Naar AM, Taatjes DJ, Zhai W, Nogales E, Tjian R (2002) Human CRSP interacts with RNA polymerase II CTD and adopts a specific CTD-bound conformation. Genes Dev 16:1339-1344

Nemet J, Jelicic B, Rubelj I, Sopta M (2014) The two faces of Cdk8, a positive/negative regulator of transcription. Biochimie 97:22-27

Odom DT, Zizlsperger N, Gordon DB, Bell GW, Rinaldi NJ, Murray HL, Volkert TL, Schreiber J, Rolfe PA, Gifford DK, Fraenkel E, Bell GI, Young RA (2004) Control of pancreas and liver gene expression by HNF transcription factors. Science 303:1378-1381

Oh KJ, Han HS, Kim MJ, Koo SH (2013) Transcriptional regulators of hepatic gluconeogenesis. Arch Pharmacal Res 36:189-200

Park JM, Kim JM, Kim LK, Kim SN, Kim-Ha J, Kim JH, Kim YJ (2003) Signal-induced transcriptional activation by Dif requires the dTRAP80 mediator module. Mol Cell Biol 23:1358-1367 
Poss ZC, Ebmeier CC, Odell AT, Tangpeerachaikul A, Lee T, Pelish HE, Shair MD, Dowell RD, Old WM, Taatjes DJ (2016) Identification of Mediator Kinase substrates in human cells using cortistatin A and quantitative phosphoproteomics. Cell reports 15:436-450

Putz EM, Gotthardt D, Hoermann G, Csiszar A, Wirth S, Berger A, Straka E, Rigler D, Wallner B, Jamieson AM, Pickl WF, Zebedin-Brandl EM, Müller M, Decker T, Sexl V (2013) CDK8-mediated STAT1-S727 phosphorylation restrains NK cell cytotoxicity and tumor surveillance. Cell Rep 4:437-444

Rachez C, Suldan Z, Ward J, Chang CP, Burakov D, ErdjumentBromage H, Tempst P, Freedman LP (1998) A novel protein complex that interacts with the vitamin D3 receptor in a ligand-dependent manner and enhances VDR transactivation in a cell-free system. Genes Dev 12:1787-1800

Rana R, Surapureddi S, Kam W, Ferguson S, Goldstein JA (2011) Med25 is required for RNA polymerase II recruitment to specific promoters, thus regulating xenobiotic and lipid metabolism in human liver. Mol Cell Biol 31:466-481

Sato S, Tomomori-Sato C, Parmely TJ, Florens L, Zybailov B, Swanson SK, Banks CA, Jin J, Cai Y, Washburn MP, Conaway JW, Conaway RC (2004) A set of consensus mammalian mediator subunits identified by multidimensional protein identification technology. Mol Cell 14:685-691

Schneider M, Hellerschmied D, Schubert T, Amlacher S, Vinayachandran V, Reja R, Pugh BF, Clausen T, Kohler A (2015) The nuclear pore-associated TREX-2 complex employs mediator to regulate gene expression. Cell 162:1016-1028

Soutourina J, Wydau S, Ambroise Y, Boschiero C, Werner M (2011) Direct interaction of RNA polymerase II and Mediator required for transcription in vivo. Science 331:1451-1454

Stevens JL, Cantin GT, Wang G, Shevchenko A, Shevchenko A, Berk AJ (2002) Transcription control by E1A and MAP kinase pathway via Sur2 mediator subunit. Science (New York, NY) 296:755-758

Sundqvist A, Bengoechea-Alonso MT, Ye X, Lukiyanchuk V, Jin J, Harper JW, Ericsson J (2005) Control of lipid metabolism by phosphorylation-dependent degradation of the SREBP family of transcription factors by SCF(Fbw7). Cell Metab 1:379-391

Taatjes DJ (2010) The human Mediator complex: a versatile, genome-wide regulator of transcription. Trends Biochem Sci 35:315-322

Taatjes DJ, Naar AM, Andel F 3rd, Nogales E, Tjian R (2002) Structure, function, and activator-induced conformations of the CRSP coactivator. Science 295:1058-1062

Takahashi H, Parmely TJ, Sato S, Tomomori-Sato C, Banks CA, Kong SE, Szutorisz H, Swanson SK, Martin-Brown S, Washburn MP, Florens L, Seidel CW, Lin C, Smith ER, Shilatifard A, Conaway RC, Conaway JW (2011) Human mediator subunit MED26 functions as a docking site for transcription elongation factors. Cell 146:92-104

Thompson CM, Young RA (1995) General requirement for RNA polymerase II holoenzymes in vivo. Proc Natl Acad Sci USA 92:4587-4590

Toth JI, Datta S, Athanikar JN, Freedman LP, Osborne TF (2004) Selective coactivator interactions in gene activation by SREBP-1a and -1c. Mol Cell Biol 24:8288-8300

Tsai KL, Sato S, Tomomori-Sato C, Conaway RC, Conaway JW, Asturias FJ (2013) A conserved Mediator-CDK8 kinase module association regulates Mediator-RNA polymerase II interaction. Nat Struct Mol Biol 20:611-619

Tsai KL, Tomomori-Sato C, Sato S, Conaway RC, Conaway JW, Asturias FJ (2014) Subunit architecture and functional modular rearrangements of the transcriptional mediator complex. Cell 157:1430-1444

Tsutsui T, Fukasawa R, Tanaka A, Hirose Y, Okhuma Y (2011) Identification of target genes for the CDK subunits of the Mediator complex. Genes Cells 16:1208-1218

Wang G, Cantin GT, Stevens JL, Berk AJ (2001) Characterization of mediator complexes from HeLa cell nuclear extract. Mol Cell Biol 21:4604-4613

Wang W, Huang L, Huang Y, Yin JW, Berk AJ, Friedman JM, Wang G (2009) Mediator MED23 links insulin signaling to the adipogenesis transcription cascade. Dev Cell 16:764-771

Wang X, Sun Q, Ding Z, Ji J, Wang J, Kong X, Yang J, Cai G (2014) Redefining the modular organization of the core Mediator complex. Cell Res 24:796-808

Wang K, Yan R, Cooper KF, Strich R (2015) Cyclin C mediates stress-induced mitochondrial fission and apoptosis. Mol Biol Cell 26:1030-1043

Westerling T, Kuuluvainen E, Makela TP (2007) Cdk8 is essential for preimplantation mouse development. Mol Cell Biol 27:6177-6182

Yang F, DeBeaumont R, Zhou S, Naar AM (2004) The activatorrecruited cofactor/Mediator coactivator subunit ARC92 is a functionally important target of the VP16 transcriptional activator. Proc Natl Acad Sci USA 101:2339-2344

Yang F, Vought BW, Satterlee JS, Walker AK, Jim Sun ZY, Watts JL, DeBeaumont R, Saito RM, Hyberts SG, Yang S, Macol C, Iyer L, Tjian R, van den Heuvel S, Hart AC, Wagner G, Näär AM (2006) An ARC/Mediator subunit required for SREBP control of cholesterol and lipid homeostasis. Nature 442:700-704

Yin JW, Liang Y, Park JY, Chen D, Yao X, Xiao Q Liu Z, Jiang B, Fu Y, Bao M, Huang Y, Liu Y, Yan J, Zhu MS, Yang Z, Gao P, Tian B, Li D, Wang G (2012) Mediator MED23 plays opposing roles in directing smooth muscle cell and adipocyte differentiation. Genes Dev 26:2192-2205

Yuan CX, Ito M, Fondell JD, Fu ZY, Roeder RG (1998) The TRAP220 component of a thyroid hormone receptor- associated protein (TRAP) coactivator complex interacts directly with nuclear receptors in a ligand-dependent fashion. Proc Natl Acad Sci USA 95:7939-7944

Zhao X, Feng D, Wang Q, Abdulla A, Xie XJ, Zhou J, Sun Y, Yang ES, Avinash M, Liu LP, Vaitheesvaran B, Bridges L, Kurland IJ, Strich R, Ni JQ, Wang C, Ericsson J, Pessin JE, Ji JY, Yang F (2012) Regulation of lipogenesis by cyclin-dependent kinase 8-mediated control of SREBP-1. J Clin Investig 122:2417-2427

Zhao J, Ramos R, Demma M (2013) CDK8 regulates E2F1 transcriptional activity through S375 phosphorylation. Oncogene 32:3520-3530

Zhao X, Xiaoli, Zong H, Abdulla A, Yang ES, Wang Q Ji JY, Pessin JE, Das BC, Yang F (2014) Inhibition of SREBP transcriptional activity by a boron-containing compound improves lipid homeostasis in diet-induced obesity. Diabetes 63:2464-2473

Zhu Y, Qi C, Jain S, Rao MS, Reddy JK (1997) Isolation and characterization of $\mathrm{PBP}$, a protein that interacts with peroxisome proliferator-activated receptor. J Biol Chem 272: 25500-25506 